\title{
LOW COVID-19 MORTALITY IN OLD AGE HOMES IN WESTERN INDIA: AN EMPIRICAL STUDY
}

Jallavi Panchamia, Mahaveer Golechha, Anushree Joshi, Bhavya Bhagat, Vishakha Bharati, Dileep Mavalankar

Indian Institute of Public Health, Gandhinagar, India

Correspondence:jallavi1@gmail.com

\begin{abstract}
BACKGROUND:

The Coronavirus disease 2019 (COVID-19) has emerged as a public health crisis globally. Management of old age homes have been challenged during the ongoing pandemic crisis, as the elderlies are by far the most vul nerable population group in context to prone to infection of COVID-19 disease.
\end{abstract}

\section{OBJECTIVE:}

The study intended to understand the effect of COVID-19 on western Indian elderly care homes, the actions taken by the administration, and the challenges faced during and post-lockdown period.

\section{METHOD:}

A total of 44 care homes across three states of western India were contacted for data collection during the period of September-December 2020. Semi-structured interviews of the administrators were taken to gather the required information to achieve the study objectives.

\section{RESULTS:}

Out of 44 care homes, ten care homes reported 169 cases of coronavirus infection and seven deaths. Hence, the rate of reported COVID-19 cases was found to be 1074 per 10,000 residents.

\section{DISCUSSION:}

Results of the study indicated the significant steps taken by these old-age care homes to stave off the infection spread among the occupants. It was observed that an average of $26 \%$ of the occupants was sent back to their home/relative's home before the lockdown to decongest the care homes. Care homes in western India seemed to have a very low infection rate and a very low number of deaths as compared to the Global Scenario. The present study also highlights the gaps in policy and calls for urgent action by the government for the regulation of old age homes in India.

\section{KEYWORDS}

Old age homes, COVID-19, Low mortality, India, Elderly, Vulnerable 
The sudden appearance of the COVID-19 epidemic has caused concerns among frontline medical staff, patients, and the general public. The WHO declared COVID-19, a pandemic on March 11, 2020, and has called for governments to take 'urgent and aggressive action' to change the course of the outbreak, especially for the vulnerable population.

COVID-19 has taken the world by storm. According to the World Health Organization, the elderly aged more than 50 years are highly susceptible to developing severe complications of COVID-19. [1] As elderlies are the age group where if the care is not taken, even due to the aging factors body's immunity goes down. [4] Hence, it is widely practiced to keep elderly people in a separate space or isolation due to the fear of family members transmitting infection to them and others. This has resulted in a higher level of anxiety and loneliness among the elderly. [5]

The elderlies are by far the most vulnerable population group in context to prone to infection of COVID-19 disease. As per the reports, age is the most important determinant in the magnitude of the spread and effect of COVID-19 disease especially after 65 years of age. [1] It has become significant to take extra care for elderly persons at home but when it comes to old age homes, this becomes a huge challenge since not just one or two, all the occupants need special care to avoid getting infected. As care homes have a unique, mixed population of staff enrolled in multiple facilities and elderly residents with multiple underlying comorbidities, it becomes difficult to avoid any occurrence of infection spread. Elderly residents are at high risk of severe complications and death due to respiratory viruses, such as influenza etc. including SARS-CoV-2 Virus.

During the initial months of the COVID pandemic, community care facilities including nursing and residential homes were termed as "hubs" and "besieged castles" in North America and Europe, having experienced large outbreaks due to rapid transmission of SARS-COV-2. whereas, Canada experienced a high number of coronavirus-related deaths in elderly care homes ${ }^{2}$. As per the global reports, England and Wales observed 45,899 deaths among care home residents between March 02 and May 02, and 12,526 got infected by COVID-19.[3] Similar experiences have been observed in France, Spain, and the United States, where only limited measures were taken. But conversely, countries like Australia, Austria, and Slovenia, which implemented "specific prevention measures" targeted at elderly care homes, including segregating units and wide screening for the COVID-19 disease, have reported fewer cases and resulted in fewer deaths. [2]

In India, according to the grey literature and news reports published, the southern part of India reported COVID-19 cases inside the old age home from Kerala, Tamil Nadu, and Karnataka [6] whereas few residents diagnosed with COVID-19 in Navi-Mumbai during OctoberNovember,2020 [7-8]. It is surprising to note that only a few news reports documented the status of old age care homes in other states of India.

In India, as cases are rising abruptly, deaths are recorded on daily basis. The rate of COVID-19 death among the elderly is high in India. Despite, hardly any studies have reported any data on the numbers of elderly residents of long-term care facilities such as nursing homes, old age homes, who might have been infected or died from confirmed or suspected coronavirus. Hence, the present study intended to understand the effect of Coronavirus disease 2019 (COVID-19) on Indian elderly care homes. The study also aimed to know the actions taken by the administration of homes and the challenges faced during the lockdown period. It would be noteworthy to understand the administrative actions taken by Indian elderly care homes during such a difficult time of pandemic. The study was conducted to explore the situation in few states of India such as Gujarat, Maharashtra, and Rajasthan, where a number of covid infection cases are substantial in general.

\section{METHODOLOGY}

\section{STUDY DESIGN:}

We adopted a qualitative study design that included indepth semi-structured interviews with administrators/managers of the old age homes. It was necessary to adopt the qualitative approach as this study required an in-depth assessment of the perceptions of administrators about the strategies adopted, challenges faced by them, which would not have been possible through a quantitative approach. 


\section{STUDY SETIINGS AND SAMPLING:}

Respondents in this study were mainly administrators/ owners/ managers of care homes in three states namely, Gujarat, Maharashtra, and Rajasthan. These three states were selected based on two rationales, the first being states with a high rate of mortality and COVID-19 infection case reported and the second being the ease of reaching the care home respondents due to available contacts and references.

\section{DATA COLLECTION AND ANALYSIS:}

Data were collected through telephonic interview by trained doctoral scholar students, Research associates, and faculty. Total 52 care homes were contacted during the months of September-December 2020, out of which 44 responded. They gave consent to give macro-level information such as the current status of COVID-19 cases/deaths, the demographic profile of occupants and related statistics before and after lockdown, available facilities, specific precautions due to pandemic, challenges, and policy changes in wake of such difficult time.

A semi-structure dinterview guide was used for conducting in-depth interviews. The main purpose of in-depth interviews was to explore the knowledge, perceptions, and experiences of administrators working in the old age homes.

Data collection was done by using semi-structured interviews, with each interview lasting for about 20-30 minutes. Initial questions included information like name and address of care homes, followed by details such as rate of occupancy before and during a pandemic reported/suspected covid infection case, and other related information. Moreover, Care homes' responses to pandemics were captured by asking open-ended questions related to challenges faced by administrators, available resources/facilities, and actions taken to avoid the occurrence and transmission of infection among elderly residents. These questions were followed by questions related to their resourcefulness, staff and medical treatment accessibility and availability; for instance, frequency of doctors/nurses' visits, isolation or quarantine facility, and basic equipment/medical kits such as thermometer, Blood-pressure measuring equipment, Oximeter, and Oxygen cylinder. Subsequently, probing questions related to staff shortage during lockdown were followed.

Right at the outset, the participants were informed about the objectives of the study, and explicit verbal consent was obtained for conducting the interviews. Additionally, the authors gave assurance to the respondents that the interviews were solely for research and was not a sponsored exercise to evaluate the care homes objectively: anonymity was also assured and safeguarded in the analysis. All interviews were conducted in the local language and translated to English during transcription by the researcher who was fluent in both languages.

From the data, a generic framework depicting factors for attraction and constraints was constructed. General themes emerged from the qualitative data, such as the resourcefulness of the old age homes, Precautions are taken to avoid transmission and challenges faced by old age homes. A few quotes have been shown in the findings to illustrate the dominant opinion of participants.

\section{RESEARCH ETHICS}

Ethical approval for this study was obtained by the Institutional Ethics Committee of Indian Institute of Public Health Gandhinagar, Gujarat and the entire study was performed by ethical standards.

\section{FINDINGS}

Key findings are given in Table 1.

\section{TABLE 1: CHARACTERISTICS OF ELDERLY CARE HOMES INCLUDED IN THE STUDY ( $\mathrm{N}=44$ )}

\begin{tabular}{|l|l|l|l|l|}
\hline & GUJARAT & $\begin{array}{l}\text { MAHARASHT } \\
\text { RA }\end{array}$ & RAJASTHAN & TOTAL \\
\hline Total old age home surveyed in India & 13 & 17 & 14 & 44 \\
\hline $\begin{array}{l}\text { Types of ownership } \\
\text { Private }\end{array}$ & 7 & 10 & 7 & 24 \\
Trust based/Public & 6 & 7 & 7 & 20 \\
\hline
\end{tabular}




\begin{tabular}{|l|l|l|l|l|}
\hline $\begin{array}{l}\text { Occupancy before lockdown (pre- } \\
\text { COVID) }\end{array}$ & 680 & 820 & 614 & 2114 \\
\hline Occupancy during COVID pandemic & $525(77 \%)$ & $598(72 \%)$ & $450(73 \%)$ & $1573(74 \%)$ \\
\hline $\begin{array}{l}\text { Occupants-Gender wise distribution } \\
\text { Male }\end{array}$ & $40 \%$ & $71 \%$ & $47 \%$ & $52 \%$ \\
\hline Female & $60 \%$ & $29 \%$ & 45 & $49 \%$ \\
\hline COVID cases reported & 44 & 80 & 2 & 7 \\
\hline Deaths reported due to COVID & 3 & 2 & 69 \\
\hline
\end{tabular}

Maharashtra (total cases $=19,60,000 \& \quad 17,150$ cases per million), Gujarat (total cases $=2,49,913, \& 3986$ cases per million) and Rajasthan (total cases $=3,11,620 \& 4,523$ cases per million) are the states situated in the western part of India and showing the higher number of cases in comparison to the other states. The most affected districts are Mumbai (total cases 2,97,638 \& 16,176 cases per million), Pune (total cases $=3,77,265, \& \quad 120,918$ cases per million) \& Nagpur (total cases $=1,29,210 \& 53,614$ cases per million) in Maharashtra, Ahmedabad (total cases 58,915 \& 10,448 cases per million), Rajkot (total cases = $20,898, \& \quad 16,200$ cases per million) \& Surat (total cases $=$ 50,554 , \& 11,334 cases per million) in Gujarat and Jaipur (total cases $=58,005, \& 18,894$ cases per million) in Rajasthan as of 10th January,2021. The old age care homes included in the study are situated in and around these districts.

As we can see from the summary table, three care homes out of 13 reported 44 cases and three deaths in Gujarat, five care homes out of 17 reported 80 cases and two deaths in Maharashtra, whereas two old age homes out of 14 reported 45 cases and two deaths in Rajasthan till we did the inquiry, i.e. $5^{\text {th }}$ January, 2021. It was found from these surveys that an average of $26 \%$ of the elderly residents left the home before the lockdown, i.e. during March-end. The same thing was seen in a total of 21 old age homes across the three states, where residents were sent back.

\section{STATUS OF COVID-19 SPREAD IN OLD AGE HOMES}

One of the old age homes in Gujarat reported 35 cases with the transmission from the administration department employee who was found to be asymptomatic covid infected. As per the information shared by the administrator, they all were shifted to the covid care centre and all recovered. Another old age home resident was diagnosed with covid when he was undergoing dialysis in the hospital. He died in the hospital itself and not in the old age home. One of the care homes in Maharashtra reported 19 covid cases during the last week of November out of the total residents of 60 , whereas another care home near Mumbai reported 40 cases and no death. These care homes surprisingly reported no death despite a significant number of cases. One of the old age homes near Jaipur in Rajasthan reported 25 cases out of the occupancy of 100 and did not report a single death. One old age home near Mumbai reported 3 cases and one death of comorbid elderly.

It was found that 40 old age homes out of 44 did not have any cases till August 2020. Although later more than 100 cases were reported in these surveyed homes during the period of September-December, only seven deaths were reported. These findings contradicted the situation of the old-age care homes in other countries, where the majority of the cases and deaths were reported from old age homes. (9-11)

\section{QUALITATIVE FINDINGS:}

\section{The resourcefulness of the old age homes}

It was found that $100 \%$ of homes were equipped with a thermometer, $95 \%$ with blood pressure measuring equipment, $70 \%$ with Oximeter but only $5 \%$ with an oxygen cylinder. All the old age homes had the regular visit of doctors, although the frequency was varying from weekly to monthly. Three care homes had a facility of resident doctors for a medical emergency and well-equipped 
hospitals to refer. While two homes had difficulty reaching out to hospitals during referral and the availability of ICU beds for COVID patients. $80 \%$ of the care homes had a facility of isolation and quarantine ready if any cases arise. COVID-19 is one of the greatest challenges we have faced during my entire tenure at old age home. We have followed the government guidelines strictly. As the elderly, are most vulnerable to COVID-19, therefore regular monitoring of their health is extremely important. We have procured the essentialmedical instruments-pulse oximeter, thermal screening equipment etc. One of the old age home administrator said.

Initially, we were scared due to COVID-19. However, we have to manage the crisis and we have arranged the frequent visit of healthcare personnel to monitor the health of the elderly and look for early symptoms if any. Further, we have also made available isolation and quarantine facility. One of the Old-age administrators shared.

Only $18 \%$ of the care homes faced the staff shortage and higher absenteeism during and after the lockdown period mainly because of their locational disadvantage being far from the city and lack of residential area nearby.

$85 \%$ of the care homes were adequately funded and had no issues with resource allocation to meet the needs of residents, but in the rest of the homes, resources were scanty to meet the requirement. In some of such NGOtrust-based old age homes, trustee kept the homes in good shape by investing their money as a philanthropic activity. As he said that these elderlies residing at this old age home is like my family, if donors do not turn up, I had to run the old age home by my fund. I cannot stop feeding my family and taking care of them.

Due to lockdown, many of the donors are not able to visit the old age home. This has led to the financial crisis for some of the old age homes. Our study revealed that old age homes are not getting much support from the government. Few administrators have informed that the appropriate government policy is not in place to provide financial and other resources to meet the demand of old age homes.

\section{Precautions taken to avoid transmission}

The administrators shared the actions taken by them to keep safe their elderly residents from getting infected with the coronavirus.
We were scared to see how old age homes in other countries were affected by covid and how difficult it was to avoid transmission from staff and outside world. So, we first stopped all contact with the outside world as much as possible. We requested our staff to live temporarily in the old age homes, thus preventing contact with the outside world. One of the administrators said.

Interestingly, $65 \%$ of the old age homes insisted their staff to stay in old age homes and not commute daily from their residence. The rest of the old age homes had a strict policy for their staff to get sanitized before entering into the premise of elderly homes. This was not seen in the majority of the western care homes, where rotation of staff among care homes was practiced. 10 Literature pointed out that the infection rate among care home residents was very high in a western country because the staff used to work in more than one old age home resulting in them being the source of transmission to elderly residents. ${ }^{15}$ Hence, such a step of insisting the old age home staff to either stay in the old age homes or enter after through sanitization helped in stopping the spread of infection.

In March 2020, when we heard that virus has entered in our state too, we thought it would be difficult to follow the norms such as physical distancing, avoid group meetings etc if we run with our full occupancy. Hence, we requested the relatives of some of our residents to take them to their home so that it would be relatively easy for us to keep the old age home away from infection transmission. One of the old age homeowners said.

Six old age homes from Gujarat, ten from Maharashtra, and five from Rajasthan saw a decrease in the elderly population due to sending them back to their relatives to decongest the old age homes Thus, it was somewhat easy for them to manage the smaller number of residents and following the physical distancing norms from all aspects.

We ensured proper sanitization of all the outside items such as vegetables etc before entering the premises. we also took utmost care of proper sanitization of the old age home premise frequently. We had to take extra care, as we have all the vulnerable groups of people living with us. One administrator said.

Most of the old age home confirmed that the safety protocols of fumigation and deep sanitization were taken periodically. All elderly residents, caretakers, staff, and administrative staff were educated for maintaining social 
distancing, wearing masks, sanitizing, other safety protocols, and preparedness.

I like the Indian food habits of our ancestors, which emphasis more on Ayurveda and Sativk food. Even before this covid came into our lives, we were preparing healthy food for our elderly residents. But soon after this virus started spreading, we started giving the ayurvedic "kadha" to everyone including residents and all the staff residing in old age homes.

Most of the administrators brought dietary changes and added certain physical activity to the routine of residents to keep them engaged and healthy. To boosts their immunity, vitamin. C, D, and multivitamins and ayurvedic "kadha" were added to their diet. The elderlies were encouraged to make video calls to their families to reduce their anxiety. No resident was allowed to go outside and there was no contact between staff who use to go outside to procure resources. Two of the care homes took special care for their bedridden elderly to avoid an outbreak situation.

\section{Challenges faced by old age homes}

It was challenging for some old age homes which were managed on a very shoestring budgets by nonprofessional philanthropic organization to ward off the probability of infection spread among their residents. Few of the care homes had enough funds to survive, whereas the majority of the old age homes faced a substantial decrease in the number of donors and funds.

Another challenge for the administrators was to keep their residents in a good mood and well-being. As one of the administrators shared, Generally, we used to take our residents for some half-day or short excursion to nearby areas to bring some change in their monotonous daily routine, but due to such unprecedented pandemic time, we could not do so. Most of the care home administrators mentioned this situation as challenging. Moreover, they could not allow their family/friends also, who generally used to come to spend quality time with their elderly residents, or for some donation and celebrations. Thus, this situation brought a lot of dullness in the lives of residents.

One of the administrators from Nashik said during the interview, we have some residents who are homeless and have no families to look after them. They are completely dependent on us, so their physical and mental well-being is our responsibility. I want to urge the authorities to regulate the news channels and other media on which all the time news will be broadcasted related to deaths due to COVID19 and chaos in different parts of the world due to COVID19. They could have shown favourable cases of recovered and about the good recovery rate along with that news so that it can bring some solace among these elderly people. Hence, this pandemic time has brought a lot of anxiety and mental well-being issues among elderly residents staying in old age homes away from their loved ones.

Although some of the old age homes made a provision for their residents of a video call with families, some lifestyle changes such as practicing yoga and meditation, etc. One of the managers at the old age home of Ahmedabad shared, we have arranged online yoga practice sessions every alternate day for our residents so that their healthy routine continues and eventually will help to enhance their overall wellbeing too. some of the administrators also arranged mental health counselling sessions for residents to improve their psychological well-being.

\section{DISCUSSION}

Unlike the "Spanish flu" of 1918, which became an international epidemic over a year, COVID-19 has spread to everyinhabitable continent within weeks, outpacing our health system's ability to test, track, and contain people with suspected infection. The demographic transition led to a significant increase in the aging population, which is a challenge for healthcare systems. Aging is often accompanied by multiple and complex health problems associated with difficulties and disabilities in daily living [9]. The pandemic has affected the vulnerable population more significantly than others and one such group is the elderly. In India about 83 million persons are 60 years of age and older, representing over $7 \%$ of the nation's total population, according to World Health Statistics 2011 [10]. The elderly people are also associated with co-morbid conditions, which again makes them more vulnerable. The present study aimed at identifying the situation of old age home during the COVID-19 pandemic, mechanisms they have put for preventing the transmission of the infection, mental health challenges occupants have faced due to the social distancing and challenges faced by old age homes.

Our study revealed that old age homes are less affected than the general population, despite residents are more vulnerable to the COVID-19. The transmission of COVID-19 
can be prevented with social distancing and other preventive measures like regular hand washing, use of mask, reducing exposure, and regular monitoring of health situation. In our study, we have found that old age homes followed the government and other guidelines strictly and this may be the reason for the low number of COVID-19 cases and mortality. However, the study also revealed that the majority of the old age homes were not prepared for public health emergencies of such magnitude. The old age homes in India are largely lack the public health orientation and staff members are not aware of preventive and public health approaches. Further, the government doesn't have any system to monitor the health of residents living in old age homes. In India, through Rashtriya Bal Swasthay Karykram (RBSK), the medical team visits schools and review the health of children. [11] This has helped in the early identification of children's diseases. A similar approach can be devised for old age homes, the government should come up with the appropriate policy, wherein nearby government health facilities can visit old age homes.

Senior citizens also need appropriate nutrition for tackling various diseases linked with poor nutrition and low immunity. Nutrition is also important to improve immunity and well-being. COVID-19 is more prevalent in people with low immunity and evidence suggests that COVID-19 is less severe in people with adequate nutrition including vitamin D level. [12] Therefore, old age homes should be equipped with nutritionist for guiding the food of residents and staff should also have orientation to nutrition. The training and capacity building of old age home staff in the area of public health, hygiene, sanitation, and nutrition should be planned. This will make them well prepared for any future public health emergency.

The total lockdown was the only immediately available, best, and ideal solution to the control COVID-19 pandemic for most of the nations. Social distancing is a critical means to break the cycle of infection. However, the lockdown, a popular policy of confinement has significant psychosocial, economic, and health consequences for a larger section of the society, especially for the elderly population. Isolation and social distancing help in achieving the goal of reducing infections, however, reduced access to family, friends, and other social support systems are linked with severe mental health issues. [13] The fear of infection, fear of death, loss of social contacts, uncertainty about various aspects of life, inadequate information, loss of outdoor and social activities, disconnection from nature, Ioneliness, depression, financial loss, and obstacles to access to essential services are key stressors during this critical period. [14] In our study, similar findings were obtained which indicated low mental well-being of residents due to curtailed access to outdoor activities, outings, lack of meetings with relatives and fear associated with the diseases. Further, the lack of mental health counselling and services exacerbated the mental health challenges for elderly residents. Access to mental health services should be made available for the elderly living in old age homes. The government through the National Mental Health Programme can take initiative for providing such services to old age home residents for helping them to improve resilience and also building coping capacity.

Our study also found that some of the old age homes also faced financial crisis due to lockdown and the pandemic. In India, the majority of old age homes are run by NGOs and social organizations and largely dependent upon the donations received from individuals and institutions. The lockdown resulted closure of transportation and mobility, which led to the unavailability of finance to run the old age homes. The Ministry of Social Justice and Empowerment is responsible for regulation and providing necessarysupport to old age homes. However, in India, old age homes are largely unregulated, and the government is not monitoring their situation regularly. The government has introduced several policies for the elderly including National Policy for Older Persons (1999), the National Initiative on Care for the Elderly (2004), and the Maintenance and Welfare of Parents and Senior Citizens Act (2007). [15] Despite the availability of several policies for the elderly, the implementation of these policies largely lacking. Recently, the Government of India has introduced the National Programme for the Health Care of the Elderly (NPHCE), aimed at prioritizing healthcare of the elderly and promoting palliative care. However, this program is largely aimed at providing institutional care and does not involves old age care homes and home-based care. In India, some states, like Kerala and Karnataka have initiated homebased care for elderly and chronically ill-patients. The Neighbourhood Network in Palliative Care in the state of Kerala includes several desired components such as care at home, caregiver support, financial aid from the community, and civil society involvement. [16] There is an urgent need to cover old age homes in the national program for the elderly and also in various government initiatives. The government should also work towards creating a robust database of all the old age homes and elderly living there. This will help in streamlining various 
strategies for improving the well-being and health of the elderly during crisis.

\section{CONCLUSION}

The present study highlights the gaps in policy for elderly care in India and calls for urgent action by the government for the regulation of old age homes in India. There is an urgent need to provide necessary resources to old age homes for improving the health and well-being of the elderly. Further, the study also come up with interesting findings about the low level of mortality in old age of homes, despite the elderly being the most vulnerable population. There are some lessons to be learned from old age homes in managing the COVID-19 pandemic and reducing the transmission. It would be interesting for clinical researchers to understand the reason behind the low mortality and low infection rate in old age homes apart from the other reasons cited in the paper. The comprehensive documentation of such practices will help devise an appropriate public health emergency in the future.

\section{LIMITATIONS OF THE STUDY}

Since the study was done through a telephonic survey, there was an absence of non-verbal cues like observing their expressions, emotions with which they talk, observing the facility itself. Some of the respondents may not have given full information during the interview due to the fear of loss of image or lack of trust., hence, the authenticity of the responses was not confirmed. There might be some sort of respondent's bias about giving positive or distorted answers regarding the covid situations to showcase the favourable picture. These gaps in the study need to be addressed with on-site observations. This study was conducted at the macro level, which could not consider the perspectives and responses of old-age home residents. Findings could have been very different if the study could have been conducted taking all the old age occupants as respondents. This study considered only tested and confirmed covid cases and not the suspected cases. Results could have been different if sero-surveillance would have been done with blood testing and our interviews could have been conducted earlier in the situation at the starting of the lockdown period.

\section{Declaration of Conflicting Interests}

The authors declare no potential conflicts of interest with respect to the research, authorship and/or publication of this article.

\section{Funding}

The authors received no financial support for the research, authorship and/or publication of this article.

\section{References:}

1. World Health Organization (WHO) Older people and COVID-19.2020; July Available:

https://www.who.int/teams/social-determinants-ofhealth/covid-19 (Assessed 12/9/20)

2. Ladhani SN, Chow JY, Janarthanan R, Fok J, CrawleyBoevey E, Vusirikala A, Fernandez E, Perez MS, Tang S, Dun-Campbell K, Wynne-Evans E. Investigation of SARS-CoV-2 outbreaks in six care homes in London, April 2020. EClinicalMedicine. 2020 Sep 1; 26:100533

3. Canada ranks worst in elderly care home coronavirus deaths: study. Medicalxpress ,2020, June 25. [Cited 20/2/20] Available from.

https://medicalxpress.com/news/2020-06-canadaworst-elderly-home-coronavirus.html

4. Asadullah M, Kuvalekar K, Katarki B, Malamardi S, Khadka S, Wagle S. A Study of Morbidity Profile and Quality of life of Inmates in Old Age Homes in Udupi District, Karnataka, India. International Journal of Basic and applied medical sciences. 2012;2(3):91-7. [cited 2020 Sep 21]. Available from: http://www.cibtech.org/ims.htm

5. Tiwari SC, Pandey NM, Singh I. Mental health problems among inhabitants of old age homes: A preliminary study. Indian journal of psychiatry. 2012 Apr;54(2):1 44.

6. Shaju Philip. Kerala: 95 COVID-19 cases in 2 old-age homes, state tightens norms | India News, The Indian Express [Internet].2020, August2, Available from: https://indianexpress.com/article/india/kerala/kerala95-covid-19-cases-in-2-old-age-homes-state-tightensnorms-6534889/

7. Vijay Kumar, S. Coronavirus | 29 senior citizens recover from COVID-19 in Chennai's Stanley Hospital. The Hindu. 2020, September 19. Available from https://www.thehindu.com/news/cities/chennai/coro navirus-29-senior-citizens-recover-from-covid-19-inchennais-stanley-hospital/article32644860.ece

8. Theresa, D. Care homes on high alert. The New Indian Express. 2020, August 4. Available at <http://cms.newindianexpress.com/cities/kochi/2020/ aug/04/care-homes-on-high-alert-2178618.html> 
9. Åberg, C., Gillsjö, C., Hallgren, J. and Berglund, M., 2020. "It is like living in a diminishing world": older persons' experiences of living with long-term health problems - prior to the STRENGTH intervention. International Journal of Qualitative Studies on Health and Well-being, 15(1), p.1747251.

10. Who.int. [cited 2021 Jan 14]. Available from: http://www.who.int/whosis/whostat/2011

11. Singh, A.K., Kumar, R., Mishra, C.K. et al. Moving from Survival to Healthy Survival through Child Health Screening and Early Intervention Services Under Rashtriya Bal Swasthya Karyakram (RBSK). Indian J Pediatr 82, 1012-1018 (2015). https://doi.org/10.1007/s 12098-015-1823-2

12. Alexander J, Tinkov A, Strand TA, Alehagen U, Skalny A, Aaseth J. Early nutritional interventions with zinc, selenium and vitamin $D$ for raising anti-viral resistance against progressive COVID-19. Nutrients. 2020;12(8):2358.

13. Zhou X, Snoswell CL, Harding LE, Bambling M, Edirippuliges, Bai $X$, et al. The role of telehealth in reducing the mental health burden from COVID-19. Telemed J E Health. 2020;26(4):377-9.

14. Matias T, Dominski FH, Marks DF. Human needs in COVID-19 isolation [published online ahead of print. J Health Psychol. 2020;2020;1359105320925149.

15. Evans JM, Kiran PR, Bhattacharyya OK. Activating the knowledge-to-action cycle for geriatric care in India. Health Res Policy Syst [Internet]. 2011 ;9 (1). Available from: http://dx.doi.org/10.1 186/1478-4505-9-42

16. Santhosh R. Voluntarism and civil society in the neoliberal era: a study on the palliative care movement in Kerala. J Soc Econ Dev. 2016;18(1-2):1-1 